NBER WORKING PAPER SERIES

\title{
DISSERTATORS WITH DISTANTLY RELATED FOCI FACE DIVERGENT NEAR-TERM OUTCOMES
}

\author{
Kevin M. Kniffin \\ Andrew S. Hanks \\ Xuechao Qian \\ Bo Wang \\ Bruce A. Weinberg \\ Working Paper 27825 \\ http://www.nber.org/papers/w27825
}

\author{
NATIONAL BUREAU OF ECONOMIC RESEARCH \\ 1050 Massachusetts Avenue \\ Cambridge, MA 02138 \\ September 2020
}

The use of NSF data does not imply NSF endorsement of the research methods or conclusions contained in this report. We are grateful to Rachel Croson, Ron Ehrenberg, Vanda Grubisic, Morgan Millar, John Siegfried, Wendy Stock, and Julie Thompson-Klein for helpful discussions on earlier versions of this work as well as seminar participants at Cornell University, The Ohio State University, and the Institute for Research on Innovation \& Science (IRIS) at the University of Michigan. Funding: This paper was supported by NSF Grant 1761086 to Kniffin and Hanks. Weinberg is grateful for support from R24 AG048059, R24 HD058484, UL1 TR000090; NSF DGE 1760544, 1535399, 1348691, and SciSIP 1064220; and the Ewing Marion Kauffman and Alfred P. Sloan Foundations. Weinberg was supported on P01 AG039347 by the NBER directly and on a subaward from NBER to Ohio State. We are grateful to ProQuest for access to their Dissertation and Thesis database. The views expressed herein are those of the authors and do not necessarily reflect the views of the National Bureau of Economic Research.

NBER working papers are circulated for discussion and comment purposes. They have not been peer-reviewed or been subject to the review by the NBER Board of Directors that accompanies official NBER publications.

(C) 2020 by Kevin M. Kniffin, Andrew S. Hanks, Xuechao Qian, Bo Wang, and Bruce A. Weinberg. All rights reserved. Short sections of text, not to exceed two paragraphs, may be quoted without explicit permission provided that full credit, including $(\odot)$ notice, is given to the source. 
Dissertators with Distantly Related Foci Face Divergent Near-Term Outcomes

Kevin M. Kniffin, Andrew S. Hanks, Xuechao Qian, Bo Wang, and Bruce A. Weinberg NBER Working Paper No. 27825

September 2020

JEL No. I23,J24,O3

\begin{abstract}
Institutional leaders have long championed interdisciplinary research; however, researchers have paid relatively little attention to the people responding to such calls and their subsequent career outcomes. With the benefit of two large datasets spanning from 1986 through 2016, we show that interdisciplinary dissertations have become consistently more common in recent years as institutional leaders have highlighted the value of boundary-spanning research for solving important and emergent problems. With the benefit of survey data from a near-complete population of all dissertators in the US starting in 2001 through 2016, we observe a consistent upward trend in interdisciplinary dissertations. Unfortunately, we show that these interdisciplinary dissertators have experienced a comparably persistent penalty when considering salaries for their first year after earning the PhD. We also show that among interdisciplinary dissertators, individuals in lower-paying fields tend to earn more when choosing distantly related topic-combinations whereas researchers in higher-paying fields tend to be most rewarded for staying within relatively narrow disciplinary silos.
\end{abstract}

Kevin M. Kniffin

Dyson School of Applied Economics

and Management

SC Johnson College of Business

Cornell University

Warren Hall 111

Ithaca, NY 14853

USA

kmk276@cornell.edu

Andrew S. Hanks

Ohio State University

130A Campbell Hall

1787 Neil Ave.

Columbus, OH 43210

hanks.46@osu.edu

Xuechao Qian

Ohio State University

Department of Economics

387 Arps Hall

1945 North High Street

Columbus, Ohio 43210

qian.211@osu.edu
Bo Wang

Ohio State University

130A Campbell Hall

1787 Neil Ave.

Columbus, OH 43210

wang.6207@buckeyemail.osu.edu

Bruce A. Weinberg

Ohio State University

Department of Economics

410 Arps Hall

1945 North High Street

Columbus, $\mathrm{OH} 43210$

and NBER

weinberg.27@osu.edu 


\section{Introduction}

\section{Dissertators with Distantly Related Foci Face Divergent Near-Term Outcomes}

Institutional leaders in academia, government, and industry often celebrate interdisciplinary research that spans traditional disciplinary boundaries - and benefits from unconventional recombinations of perspectives - as critical for solving new, emergent, and very important problems (e.g., National Research Council, 2014; Roco \& Bainbridge, 2013; Sharp, Jacks, \& Hockfield, 2016). The call for people to conduct interdisciplinary research, though, runs against the grain of academic disciplines that provide "recipes" for addressing various sets of focal problems (Hackett \& Rhoten, 2009). The tension between these tendencies to champion interdisciplinary work while acknowledging the power of specialized academic disciplines is visible in numerous bibliometric studies that have tended (with exceptions) to show relatively less impact generated by interdisciplinary research (Leahey, Beckman, Stanko, 2017; Millar, 2013; Rafols et al., 2012; Seibert et al., 2017). Among the groups of people who need to navigate these countervailing pressures that differentially affect people across career stages (Rhoten \& Parker, 2004), the population of graduate students warrants particular attention since all dissertators work within academia and, consequently, actively engage in institutions that paradoxically champion interdisciplinary research while concurrently rewarding monodisciplinary activities. Graduate students are also important to study since doctoral training is a formative career stage with long-term consequences that extend beyond the dissertation.

In contrast with the bibliometric studies that measure the performance of interdisciplinary research through publications, citations, and/or patents, this paper focuses on understanding the career-level paths that graduate students encounter when they do or do not conduct

interdisciplinary dissertation research. More specifically, we focus on the population of graduate students in the United States and examine (i) whether there has been a trend over time with respect to the percentage of dissertations that are interdisciplinary; (ii) the extent to which there are demographic factors that appear to influence whether a person conducts interdisciplinary research as a graduate student; and, (iii) the degree to which interdisciplinary dissertators are either rewarded or penalized in terms of their initial career outcomes.

Our analyses show that there has been a substantial increase in the percentage and number of interdisciplinary dissertations; there are not overwhelming demographic differences when comparing interdisciplinarians and monodisciplinarians; and, despite the increase in 
interdisciplinarity, there appears to be a persistent penalty incurred by interdisciplinary dissertators over time, even when controlling for demographic and disciplinary variables. Further, when we consider the distance between topics that interdisciplinarians integrate in their work, there is a tendency for individiduals in lower-paying fields (Life Sciences, Math, and Humanities) who combine distantly related topics to enjoy near-term advantages; however, individuals in higher-paying fields (Engineering and Business) tend to enjoy higher starting salaries if they avoid interdisciplinary pursuits, especially with more distant fields.

The Survey of Earned Doctorates (SED) sponsored by the National Science Foundation (NSF) has long been a part of the graduation process for everyone earning a $\mathrm{PhD}$ in the United States. The survey started tracking interdisciplinary dissertations in 2001 <https://www.nsf.gov/statistics/srvydoctorates/> and began measuring salaries for the year after earning a $\mathrm{PhD}$ in 2008. With the restricted-access microdata that is generated through the SED, our analyses utilize the dissertation field data and demographic information provided by doctoral graduates as well as several measures of near-term employment outcomes (e.g., salaries). Our analyses draw on responses from slightly more than 688,000 people who earned doctoral degrees in the US between 2001 and 2016. As a complement to the SED microdata, we also utilized dissertation data available from ProQuest in order to assess trends in interdisciplinarity over a longer period of time (1986-2015) with the benefit of data from 1,009,954 dissertations. Our work was approved by Ohio State University and Cornell University institutional review boards.

\section{Data and Empirics}

To measure interdisciplinarity trends over time, we rely on two sets of data that provide dissertation fields for PhD recipients: a) the Survey of Earned Doctorates (SED) and b) ProQuest Dissertations and Theses. The National Science Foundation's (NSF) National Center for Science and Engineering Statistics (NCSES) oversees the SED and relies on individual responses for most of the data and then uses information from commencement programs and university websites for the remaining individuals. SED respondents specify their dissertation field by selecting from a list of over 300 fields. Each individual field also exists within a broader, more general, area. In 2001, NCSES included a question asking whether $\mathrm{PhD}$ recipients had a secondary field for their dissertation. Upon answering yes, respondents could then enter the code for the secondary field. Since then, NCSES has slightly modified this question to allow 
respondents to enter more fields and to ask if the research is interdisciplinary. These modifications do not influence overall trends in interdisciplinarity.

The ProQuest Dissertation \& Theses data is the world's largest curated collection of dissertations and theses and the official offsite dissertation repository for the U.S. Library of Congress. It contains dissertations published from 1861 and documents the comprehensive information of each dissertation, including a unique publication identifier, research subject, institution information (a school identifier and name), and the degree information of the recipient (the degree and date). In this study about interdisciplinary dissertations, we focus on Ph.D. recipients who graduated from US institutions after 1985, when multiple fields on one dissertation started to be recorded in the Subject variable of by ProQuest. Therefore, we analyze 1,009,954 dissertations from Ph.D. recipients between 1986 and 2015 and parse the fields listed for each dissertation (i.e., our sample stops with 2015 due to incomplete information for 2016). Similar to the SED, each individual field in ProQuest can be classified into a broader and more general area. To be consistent with the SED, we categorize them into 11 major areas: life sciences, engineering, computer and information science, mathematics and statistics, physical sciences, psychology, social sciences, humanities, education, business, and communication.

\subsection{Measures of Interdisciplinarity}

In this work, we use three measures of interdisciplinarity. For the first "General” measure, we classify someone as interdisciplinary if they indicate a second dissertation field (SED) or indicate a second field (ProQuest). We separate this measure into Global and Local interdisciplinarian subsets. We characterize Global interdisciplinarians as those who select a secondary field outside of their primary top-level field. Conversely, we label respondents as Local interdisciplinarians if their secondary field falls within the same primary top-level field. For example, we would classify an individual with a primary field of Civil Engineering and a secondary field of Mechanical Engineering as a Local interdisciplinarian since both fields fall under the top-level field of Engineering. Moreover, we would classify an individual with a primary field of Organic Chemistry and a Secondary Field of Biotechnology as Globally interdisciplinary since Organic Chemistry falls under the top-level field of Physical Sciences while Biotechnology falls under the top-level field of Life Sciences. Interested readers can view 
the nested or hierarchical taxonomy of fields at the following site:

<https://www.nsf.gov/statistics/srvydoctorates/>.

\subsection{Measures of Outcomes}

Our interest is to understand the prevalence of interdisciplinarity over time as well as the near-term success of interdisciplinary $\mathrm{PhDs}$ recipients in the job market. Consequently, our outcome measurements include the three different interdisciplinarity variables we construct from the SED data. In addition to these outcomes, we also use a variable that indicates whether the individual accepted a postdoctoral research position, or a position in academia, industry, or government. Lastly, since 2008, the SED has collected data on self-reported salary and we use this information to study whether interdisciplinary dissertators receive a salary premium or face a salary penalty.

\subsection{Covariates}

In our empirical models, we control for a variety of individual and institutional characteristics to reduce the possibility that patterns we observe in interdisciplinarity over time and associations between interdisciplinarity and our other outcomes are driven by individual and/or institutional characteristics. For individual characteristics, we include the respondent's age, sex, marital status (married or not), US citizenship status, race, and level of parental education. We also include characteristics of the respondent's educational experience including whether the degree granting institution is public or private, the degree granting institution's Carnegie Classification for research activity (R1, R2, R3, or R4), and whether the respondent worked as a research assistant during graduate school. To capture year-by-year variation, we also include yearly indicator variables.

\section{Empirical Models}

We estimate several regressions to track the prevalence of interdisciplinary dissertators over time, the degree to which covariates correlate with interdisciplinary research, and how interdisciplinary dissertators fare in the job market. In each regression, we include our set of covariates. To account for the non-independence of observations within universities, we also cluster our standard errors by field. While we do not use hierarchical linear models, clustering standard errors addresses the fact that our observations, $\mathrm{PhD}$ recipients, are nested within universities. In the regressions where we use job placement (postdoc, academia, industry, or 
government) as outcomes, we also include an interdisciplinarity measure. As a result, for each of these outcomes, we have three different regressions corresponding to the three measures of interdisciplinarity.

\section{Results}

Figure 1A shows a robust uptrend from 2001-2016 in the percentage of interdisciplinary dissertations. While there are some year-to-year fluctuations, the uptrend is visible for all 3 measures of interdisciplinarity that we computed: "Interdisciplinary: General”, “Interdisciplinary: Local”, and "Interdisciplinary: Global”. Following the convention established in prior work (Barringer, Leahey, \& Salazar, 2020; Kniffin \& Hanks, 2017; Millar, 2013), "Interdisciplinary General” classifies all dissertations with a secondary field as interdisciplinary and is the sum of the "local” and "global” measures. Our identification of local and global interdisciplinarity relies upon the two levels of field-categories - aggregated (or top-level) and fine (or bottom-level) - established through the field list available in the SED. As a result, we classify dissertations with primary and secondary fields (e.g., Evolutionary Biology and Horticulture Science) in the same top-level category (e.g., Life Sciences) as “locally” interdisciplinary while dissertations with fields in different top-level categories (e.g., Robotics in Engineering and Economics in Social Sciences) as "globally” interdisciplinary. Complementary to the uptrend in interdisciplinarity, Figure 1A also shows the downtrend (but still predominance) of monodisciplinary dissertations (overall rate of 73.1\% across 2001-2005 to 59.5\% across 201116).

Insert Figure 1 here

To identify which disciplines tend to foster interdisciplinary dissertations and how those propensities have evolved, Figure 1B shows how the uptrend in interdisciplinarity has occurred across each of the aggregate or top-level field categories. As a share of total $\mathrm{PhD}$ recipients within each top-level category, the Physical Sciences, Humanities, and Communications generate the highest percentages of interdisciplinary dissertators. Figure $1 \mathrm{C}$ indicates - for the full sample of dissertations that list more than one dissertation field - the frequency of secondary-field pairings (on the right side) associated with each primary field (on the left side). 
The thickness of the bands that stay within a given top-level category reflect "locally" interdisciplinary dissertations whereas the bands that start in one top-level category and mix with another top-level category reflect the relative frequency and nature of "globally" interdisciplinary dissertations. Within the top-level field categories, the proportion of dissertations that are generally interdisciplinary ranges from 23\% (Math) to 39\% (Life Sciences) and 43\% (Communication). Appendix Figure 1 illustrates a similar patterns in terms of trends over time, differences across fields, and patterns of field pairings using ProQuest data spanning 1986 through 2015.

Figure 2A shows, based on sample means, that general interdisciplinarians - and within that group, Local interdisciplinarians - appear, consistently across the span of 2008-2016, to be paid less than others in the year after earning a $\mathrm{PhD}$. It is equally remarkable and intriguing in Figure 2A that Global interdisciplinarians appear to have earnings that are approximately equivalent to monodisciplinarians.

Insert Figure 2 here

One important consideration regarding salaries is recognition that salaries tend to be substantially higher for those working in industry compared with other sectors (e.g., Hanks \& Kniffin, 2014). As is visible in Figure 2B, there is variation in employment sector across (inter)disciplinary categories. $17.4 \%$ of monodisciplinarians tend to go to industry compared with $14.8 \%$ of the interdisciplinarians; however, it is equally notable that $16.1 \%$ of the global interdisciplinarians went to work in industry compared with $13.9 \%$ of the local interdisciplinarians. Similarly, it is helpful to recognize that - while local interdisciplinarians more commonly become postdocs than monodisciplinarians - the global interdisciplinarians are more like the monodisciplinarians in that regard. Specifically, $51.9 \%$ of the local interdisciplinarians choose to take postdoc positions compared with $41.8 \%$ of the global interdisciplinarians and $41.4 \%$ of the monodisciplinarians. We report full descriptive statistics in Table 1.

Insert Table 1 here 
Figure 2C, which includes the full SED sample from 2001-2016, shows that there exists minimal variation across the demographic categories in the percentages of interdisciplinary dissertators. Notably, the percentages of and interdisciplinary dissertators are basically equivalent for men and women and whether someone was a first-generation college graduate or completed their doctoral studies at a research-intensive (R1) university. We include the descriptive statistics for these variables in Table 2.

Insert Table 2 here

While individual demographic characteristics do not differ dramatically with respect to (inter-)disciplinarity, there are a few meaningful differences. For instance, with respect to citizenship, fewer US citizens complete interdisciplinary dissertations compared with noncitizens (63\% of interdisciplinarians are US citizens while $66 \%$ of monodisciplinarians are US citizens), but there are no meaningful differences in terms of global versus local interdisciplinarity by citizenship. With respect to race, we find that White doctoral graduates are more likely to have completed monodisciplinary dissertations (i.e., 64\% of interdisciplinarians are White while almost $68 \%$ of monodisciplinarians are White). While there is a substantial positive correlation between White and US citizen $(r=.55, p<.01)$, the models that we report

below take into account demographic characteristics when assessing the existence and size of differences between interdisciplinarians and monodisciplinarians. Such consideration of demographic variables for understanding innovative research is visible in recent findings (Hofstra et al., 2020) showing that individuals from historically under-represented groups disproportionately produce such work. Our analyses, though, importantly consider citizenship as a covariate given well-established findings (Hunt \& Gauthier-Loiselle, 2010; Stephan \& Levin, 2001) that immigrants (compared with non-immigrants) are more likely to be innovative.

\subsection{Upward Trend in Interdisciplinary Dissertations}

It is clear from our analyses of the SED as well as ProQuest dissertation data that there are uptrends in interdisciplinarity in recent decades. On the one hand, the uptrend in interdisciplinary dissertations should not be surprising given the frequency of institutional 
leaders calling for more boundary spanning work as well as prior research charting attitudes towards interdisciplinary research (Klein, 1990). On the other hand, beyond the disciplines providing “recipes” for individuals to succeed (Hackett \& Rhoten, 2009), it is also true that among academics at least - there tend to be suspicions cast on those who breach a given discipline’s bounds (Abbott, 2010; Campbell, 1969). For example, at the same time that institutional leaders might include interdisciplinary programs as part of their strategic plans (Barringer et al., 2020), there also exist researchers who take care - often for good reasons - to guard against “epistemic trespassing” (Ballantyne, 2019).

We can use our classification of dissertations as locally or globally interdisciplinary to understand the degree to which $\mathrm{PhD}$ students diversify their training. Specifically, local interdisciplinarians choose secondary fields closely related to their primary field. Consequently they diversify their skill set less relative to global interdisciplinarians who select more distantly related fields. Notably, we observe that between these two groups of interdisciplinarians, global interdisciplinarians have become more frequent - and with relatively greater speed (from 7.8\% of all $\mathrm{PhD}$ recipients in 2001 to 19.6\% in 2016) - compared to the percentage of $\mathrm{PhD}$ recipients completing a locally interdisicplinary dissertation (16.2\% in 2001, escalating to $25.1 \%$ in 2016).

Job placement outcomes also highlight differences between local and global interdisciplinarians. Most notably, global interdisciplinarians track placements of monodisciplinarians very closely. In both categories, 25\% accept positions in Education and both are very close in Postdoctoral and Industry placements. Figure 2B makes it clear, though, that a higher percentage of local interdisciplinarians select Postdoc positions and that they account for the greater share of general interdisciplinarians compared to monodisciplinarians taking Postdoc positions. If interdisciplinarians entered postdoc positions because successful interdisciplinary work required more training, in contrast to what we find, one might have expected more global interdisicplinarians to take postdocs. As with our consideration of demographic characteristics, these placement findings are interesting on their surface since they speak to the risks and rewards of interdisciplinary work, and they are key for the analysis below.

\subsection{Stable Penalty Incurred by Interdisciplinary Dissertators}

If the labor market for people earning a PhD truly valued interdisciplinary research, then we would expect to see interdisciplinarians earn higher wages across most, at least, top-level 
fields. The patterns we observe in Figure 1A and Figure 2A suggest just the opposite: interdisciplinarians have experienced a persistent and stable near-term penalty. Among the possible reasons for this stable penalty, which persists even with the overall drop in salaries that occurred in the wake of the 2008-9 financial crisis in the United States, a lack of information among market participants may be important. Standard labor economics would predict that in the absence of other factors, such as a preference for doing interdisciplinary work, people in a given market should gain awareness of various penalties associated with a given activity and, in turn, people should start avoiding whatever activity incurs a penalty.

In this case, the stability of the penalty suggests at least two possible explanations: 1) that a substantial percentage of dissertators in the United States are taking on interdisciplinary dissertations with either "naive optimism” (Golde \& Dore, 2001) whereby they do not have an understanding of the likely penalty, or 2) perhaps willful optimism whereby they are sufficiently motivated by personal preference to study the topic of their choice and the relative penalty does not deter them. With respect to willful optimism and preferences, one would expect that dissertators from more privileged backgrounds may be more able and willing to accept a salary penalty but we see in Figure 2C (and Table 3) that proxies for students' family background (parental education levels) do not show a strong difference when comparing interdisciplinarians and monodisciplinarians.

Insert Table 3 here

Considering Figure 2A more closely, it is interesting to recognize that while "local" interdisciplinarians (e.g., people indicating expertise in two subfields within the Life Sciences, for example) are closer to being monodisciplinary in terms of field proximity, they are also the main reason why there is an apparent penalty for conducting interdisciplinary research. In other words, there is an apparent tension because the people who bridge distantly related fields and might be perceived to be overly ambitious tend to have better near-term outcomes, at least, than those who mix closely related fields. It is interesting in this context that the global interdisciplinarians also tend to take slightly longer to complete their degree programs (see Table 1) - a pattern that makes sense given the lower amounts of redundant or overlapping content that would be found in globally interdisciplinary dissertations. Separate from other potential 
explanations for the persistent penalty incurred by (local) interdisciplinarians, another intriguing possibility relates to the dynamic nature of how fields are related to each other and how fields form. As Brint et al. (2009) note, there are reasons to expect that interdisciplinary combinations that become common and successful enough will tend to become institutionalized and emerge as distinct fields of their own over time. Indeed, the SED field listing does periodically update its categorization of dissertations so it is reflective of the subjects that dissertators examine.

Consequently, if it were the case that there was significant and relatively rapid shifting of fields, then the pattern that we see of a persistent penalty for interdisciplinary dissertations could be reflected in a steady stream of new interdisciplinary combinations. As is visible in SI Appendix Figure 2, we do not see evidence of such rapid shifting; consequently, the persistent penalty faced by interdisciplinarians does not appear to be an artifact of newly emergent fields.

As previewed in prior sections, closer consideration of the role of placement offers additional insight into the salary penalty that is visible in Figure 2A. As is visible in SI Appendix Figure 3, we used linear regression methods to study how much of the interdisciplinary salary penalty observed in Figure 2A is influenced by demographic and institutional characteristics. Our analyses show that after we control for demographics and institutional characteristics, we observe a very similar pattern as Figure 2A; however, when we control for top-level field categories as well as placement (i.e., sector or type of employment after earning the $\mathrm{PhD}$ ), there is a tightening or minimizing of the differences that we see in Figure 2A. A benefit of the contrasting models that we visualize in SI Appendix Figure 3 is that the differences indicate that further nuance is needed to make sense of the patterns visible in Figures 1 and 2.

\subsection{Distantly Related Combinations are More Valued than Closely Related Combinations in Higher-Paying Fields}

Figure 3 integrates our analyses and illustrates model-estimated means for each top-level field for the near-term salaries earned by general, global, and local interdisciplinarians alongside monodisciplinarians. In these analyses we control for individual and institutional demographics and job placement. With the benefit of this fine-grained approach, we can see that in lowerpaying fields (Life Sciences, Math, and Humanities), global interdisciplinarians tend to have earnings that are higher than monodisciplinarians while Monodisciplinarians tend to have 
earnings that are higher than others in higher-paying fields (Engineering and Business). These patterns are interesting for several reasons.

Insert Figure 3 here

First, it seems sensible in hindsight, at least, that people whose fields tend to command relatively lower earnings may derive financial benefits by commingling their work with aspects of more highly compensated fields. In other words, while decisions relating to graduate education are a multifaceted product of preferences as well as earnings (e.g., earnings are low in the Humanities given the length of training), people in lower paying fields can increase earnings by becoming global interdisciplinarians. Indeed, this pattern complements prior research among undergraduates examining which double-major combinations are more likely to associated with higher returns after graduation (Del Rossi, Alison, \& Hersch, 2016).

Second, to consider our findings in relation to more conventional or popular treatments of people who are "too spread out," our findings suggest that there are parts of the post-PhD labor market that tend to reward wide-ranging generalists while other parts tend to guard against would-be interlopers. It is an interesting sociological puzzle - outside of our scope - to consider why and how such differences across disciplines exist and operate; however, our findings suggest that there may be variations across disciplines with respect to the relative degree of ethnocentrism and/or transdisciplinary orientation (Misra, Stokols, \& Cheng, 2015). More specifically, prior research examining how different fields treat interdisciplinary products (e.g., based on citation count) does not consider the substantial variation that exists among categories of fields. Our work brigdes this gap and shows that there appear to be incentives for wideranging work, especially in lower-paying fields along with incentives for narrow work in higherpaying fields. In other words, Figure 3 makes it clear that financial incentives for "optimal distinctiveness” (Leonardelli, Pickett, \& Brewer, 2010) are not uniform across top fieldgroupings and that different fields clearly reward wide-ranging research differently.

Third, we know from preliminary analysis that the inverse relationship between near-term salaries and global interdisciplinarity at the level of aggregate fields also appears to have some analogues among finer-grained fields. For example, within the top-level category of Psychology, the specific field of Industrial and Organization Psychology is the highest paying field and has 
the lowest percentage of dissertators who combine their work with topics outside of Psychology. We observe similar patterns for the specific field of Information Science and Systems within the top-level category of Computer Science and the specific field of Veterinary Sciences within the aggregated Life Sciences.

\section{Limitations and Future Directions}

Our focus on the individual-level career experiences is responsive to calls from researchers studying institutional and bibliometric patterns related to interdisciplinarity (e.g., Carr, Loucks, \& Blöschl, 2018; Solomon et al., 2019) to understand more closely "who” is conducting the work and how do their careers tend to unfold. Limitations of the current research relate to potential endogeneity associated with individual decisions to conduct interdisciplinary dissertation research. We emphasize, though, that our objective is to establish annual trends and provide an overall picture of demographic characteristics of interdisciplinarians compared to mono-disciplinarians, the institutions where interdisciplinarians tend to receive PhDs, and nearterm outcomes as available in the SED data. We recognize that this approach overlooks important statistical considerations, such as endogeneity, and we expect future researchers will find appropriate ways to handle the endogeneity concerns and provide greater clarity to these important questions. We do, though, emphasize that in the absence of available instrumental variables that would allow for causal analysis, we control for a wide range of potential confounding factors that could be plausibly related to wage effects associated with interdisciplinary research.

Future research should also more closely examine the origins and mechanisms of the divergent incentive-related patterns that we see among categories of fields. For example, the concept of "social closure" (Weeden, 2002) seems to align with the findings whereby higherpaying fields effectively penalize members of the field for commingling their work with distantly related fields. Recent work by Haeussler and Sauermann (2020) showing a positive association between interdisciplinarity and division of labor within scientific teams also warrants closer attention as a mechanism given that there also exists evidence that STEM doctoral graduates who participate in teamwork (i.e., dividing up labor) tend to earn significantly higher wages (Kniffin \& Hanks, 2018). In other words, the relatively low rates of teamwork in certain fields (e.g., 
Humanities) (Wuchty, Jones, \& Uzzi, 2007) is a potential factor that future research should consider.

For empirical extensions of our findings, researchers should examine a broader array of individual-level outcomes (e.g., health [Levecque et al., 2017]) alongside salary and placement. In addition, a longer series of data that permit consideration of longitudinal patterns that might accrue to people who conduct monodisciplinary or various kinds of interdisciplinary dissertation research would be valuable. In that respect, a better understanding of who conducts interdisciplinary research in mid- or late-career stages (D’Este et al., 2019) would also be informative since it is very plausible that people who conducted monodisciplinary dissertations as graduate students become interdisciplinarians later in their careers.

\section{Conclusion}

Interdisciplinary research is often celebrated at high administrative levels; however, research on the products of interdisciplinary work (e.g., publications) have shown mixed outcomes while studies of the individuals who take on the challenge of interdisciplinarity have shown inferior outcomes. Our analyses focus on understanding the dissertators and new doctoral graduates in the United States during a substantial span of recent years and we see that there is an apparent, persistent salary penalty paid across fields for writing interdisciplinary dissertations;

however, there are more specific patterns whereby dissertators who bridge relatively large distances are rewarded in lower-paying fields and penalized in higher-paying fields. 


\section{References}

Abbott, A. (2010). Chaos of disciplines. Chicago, IL: University of Chicago Press.

Ballantyne, N. (2019). Epistemic trespassing. Mind. 128, 367-395.

Barringer, S. N., Leahey, E., \& Salazar, K. (2020). What Catalyzes Research Universities to Commit to Interdisciplinary Research? Research in Higher Education, 61, 679-705.

Brint, S. G., Turk-Bicakci, L., Proctor, K., \& Murphy, S. P. (2009). Expanding the social frame of knowledge: Interdisciplinary, degree-granting fields in American colleges and universities, 1975-2000. The Review of Higher Education, 32(2), 155-183.

Campbell, D. T. (1969). Ethnocentrism of disciplines and the fish-scale model of omniscience. Interdisciplinary relationships in the social sciences, 328, 348.

Carr, G., Loucks, D. P., \& Blöschl, G. (2018). Gaining insight into interdisciplinary research and education programmes: A framework for evaluation. Research Policy, 47(1), 35-48.

Del Rossi, Alison F., and Joni Hersch. (2016). The Private and Social Benefits of Double Majors. Journal of Benefit-Cost Analysis, 7(2), 292-325.

D’Este, P., Llopis, O., Rentocchini, F., \& Yegros, A. (2019). The relationship between interdisciplinarity and distinct modes of university-industry interaction. Research Policy, 48(9), 103799.

Golde, C. M., \& Dore, T. M. (2001). At cross purposes: What the experiences of today's doctoral students reveal about doctoral education. phd-survey.orgHackett, E. J., \& Rhoten, D. R. (2009). The snowbird charrette: Integrative interdisciplinary collaboration in environmental research design. Minerva, 47, 407-440.

Hanks, A. S., \& Kniffin, K. M. (2014). Early career PhD salaries: The industry premium and interdisciplinary debate. Applied Economics Letters, 21(18), 1277-1282.

Haeussler, C., \& Sauermann, H. (2020). Division of labor in collaborative knowledge production: The role of team size and interdisciplinarity. Research Policy, 49(6), 103987.

Hofstra, B., Kulkarni, V. V., Galvez, S. M., He, B, Jurafsky, D., \& McFarland, D. A. (2020). The Diversity-Innovation Paradox in Science. Proceedings of the National Academy of Sciences, 117(17), 9284-9291.

Hunt, J., \& Gauthier-Loiselle, M. (2010). How much does immigration boost innovation? American Economic Journal: Macroeconomics, 2(2), 31-56.

Klein, J. T. (1990). Interdisciplinarity: History, theory, and practice. Detroit, MI: Wayne State University Press. 
Kniffin, K. M., \& Hanks, A. S. (2017). Antecedents and near-term consequences for interdisciplinary dissertators. Scientometrics, 111(3), 1225-1250.

Kniffin, K. M., \& Hanks, A. S. (2018). The trade-offs of teamwork among STEM doctoral graduates. American Psychologist, 73(4), 420-432

Leonardelli, G. J., Pickett, C. L., \& Brewer, M. B. (2010). Optimal distinctiveness theory: A framework for social identity, social cognition, and intergroup relations. In Advances in experimental social psychology (Vol. 43, pp. 63-113). Academic Press.

Levecque, K., Anseel, F., De Beuckelaer, A., Van der Heyden, J., \& Gisle, L. (2017). Work organization and mental health problems in PhD students. Research Policy, 46(4), 868-879.

Misra, S., Stokols, D., \& Cheng, L. (2015). The transdisciplinary orientation scale: Factor structure and relation to the integrative quality and scope of scientific publications. Journal of Translational Medicine and Epidemiology, 3(2), 1042.

Leahey, E., Beckman, C. M., \& Stanko, T. L. (2017). Prominent but less productive: The impact of interdisciplinarity on scientists' research. Administrative Science Quarterly, 62(1), 105-139

Millar, M. M. (2013). Interdisciplinary research and the early career: The effect of interdisciplinary dissertation research on career placement and publication productivity of doctoral graduates in the sciences. Research Policy, 42(5), 1152-1164.

National Research Council. (2014). Convergence: facilitating transdisciplinary integration of life sciences, physical sciences, engineering, and beyond. National Academies Press.

Rafols, I., Leydesdorff, L., O’Hare, A., Nightingale, P., \& Stirling, A. (2012). How journal rankings can suppress interdisciplinary research: A comparison between innovation studies and business \& management. Research Policy, 41, 1262-1282.

Rhoten, D., \& Parker, A. (2004). Risks and rewards of an interdisciplinary research path. Science, 306, 2046.

Roco, M. C., \& Bainbridge, W. S. (Eds.). (2013). Converging technologies for improving human performance: Nanotechnology, biotechnology, information technology and cognitive science. Springer Science \& Business Media.

Seibert, S. E., Kacmar, K. M., Kraimer, M. L., Downes, P. E., \& Noble, D. (2017). The role of research strategies and professional networks in management scholars' productivity. Journal of Management, 43(4), 1103-1130.

Sharp, P., Jacks, T., \& Hockfield, S. (2016). Capitalizing on convergence for health care. Science, 352(6293), 1522-1523. 
Solomon, G. E., Youtie, J., Carley, S., \& Porter, A. L. (2019). What people learn about how people learn: An analysis of citation behavior and the multidisciplinary flow of knowledge. Research Policy, 48(9), 103835.

Stephan, P. E., \& Levin, S. G. (2001). Exceptional contributions to US science by the foreignborn and foreign-educated. Population research and Policy review, 20(1-2), 59-79.

Weeden, K. A. (2002). Why do some occupations pay more than others? Social closure and earnings inequality in the United States. American Journal of Sociology, 108(1), 55-101.

Wuchty, S., Jones, B. F., \& Uzzi, B. (2007). The increasing dominance of teams in production of knowledge. Science, 316(5827), 1036-1039. 
Acknowledgments: We are grateful to Rachel Croson, Ron Ehrenberg, Vanda Grubisic, Morgan Millar, John Siegfried, Wendy Stock, and Julie Thompson-Klein for helpful discussions on earlier versions of this work as well as seminar participants at Cornell University, The Ohio State University, and the Institute for Research on Innovation \& Science (IRIS) at the University of Michigan. Funding: This paper was supported by NSF Grant 1761086 to Kniffin and Hanks. Weinberg is grateful for support from R24 AG048059, R24 HD058484, UL1 TR000090; NSF DGE 1760544, 1535399, 1348691, and SciSIP 1064220; and the Ewing Marion Kauffman and Alfred P. Sloan Foundations. Weinberg was supported by NIA, OBSSR, and NSF SciSIP on P01 AG039347 by the NBER directly and on a subaward from NBER to Ohio State. We are grateful to ProQuest for access to their Dissertation and Thesis database. The use of National Science Foundation (NSF) data does not imply NSF endorsement of the research, research methods, or conclusions contained in this report. Author contributions: K.M.K, A.S.H., X.Q. B.A.W., and B.A.W. designed research; A.S.H., X.Q. and B.A.W. analyzed data; and K.M.K. A.S.H., X.Q., B.W., and B.A.W. wrote the paper. Competing interests: Authors declare no competing interests. Data and materials availability: Microdata that we examined from the National Science Foundation's Survey of Earned Doctorates (SED) is Restricted but accessible via license agreements we have with the NSF. Data that we examined from ProQuest is Restricted but accessible via a Data Use Agreement with ProQuest. 
Figure 1: Trends in (inter-)disciplinarity of dissertations overall, by field and field-combinations. A shows the relative and consistent decline in monodisciplinary dissertations and accompanying increase in local, global, and general interdisciplinary work. B shows the proportion of interdisciplinarians within each each top-level field and how the uptrend in interdisciplinary work is common across toplevel dissertation (aggregated) fields. C illustrates - for interdisciplinary dissertators - which secondary top-level fields (right side) accompany the primary top-level fields (left side). Interdisciplinary dissertators more commonly combine "local” subfields, direct connection from left to right, that are part of the same top-level category. The chart also shows the relative frequency of "global" combinations, connection from one top-level field to another, across top-level categories. The numbers in parentheses give the share of dissertations in each field that are interdisciplinary generally. Data represent dissertations completed in the United States between 2001 and 2016 based on the Survey of Earned Doctorates (SED).

A.

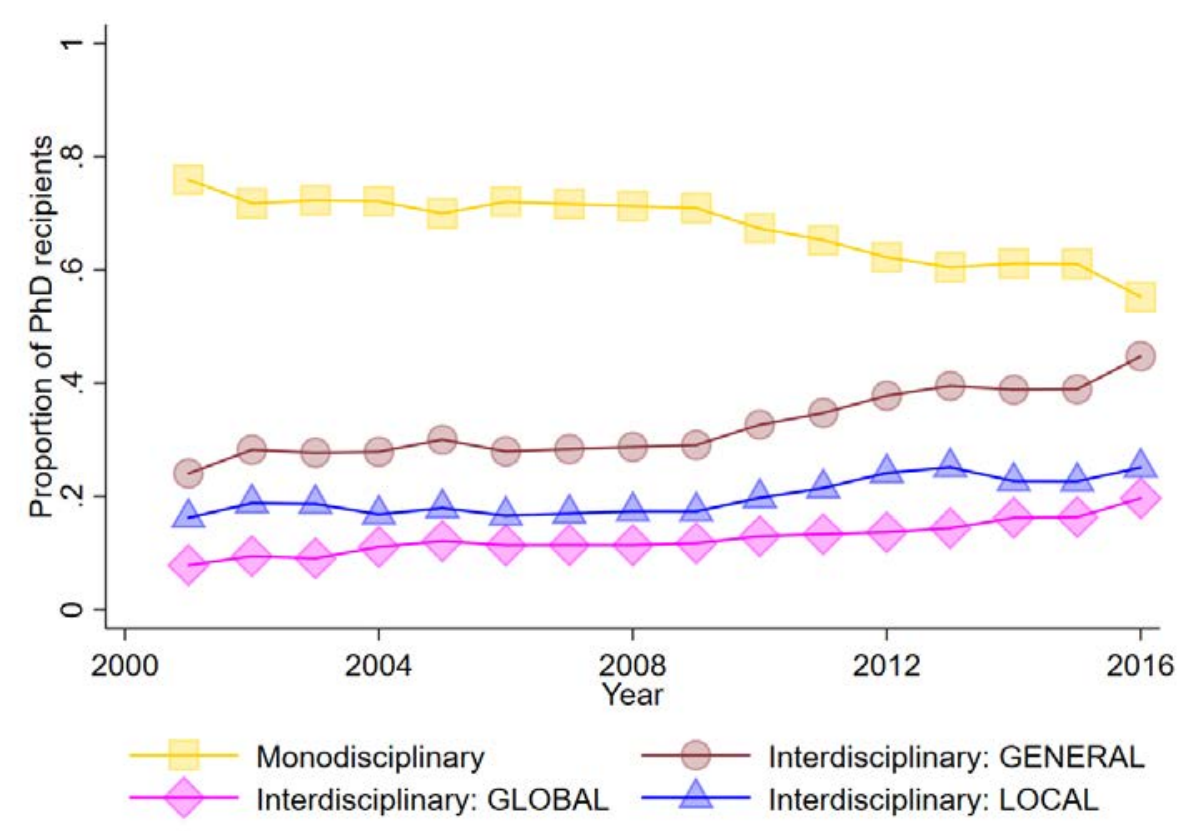


B.

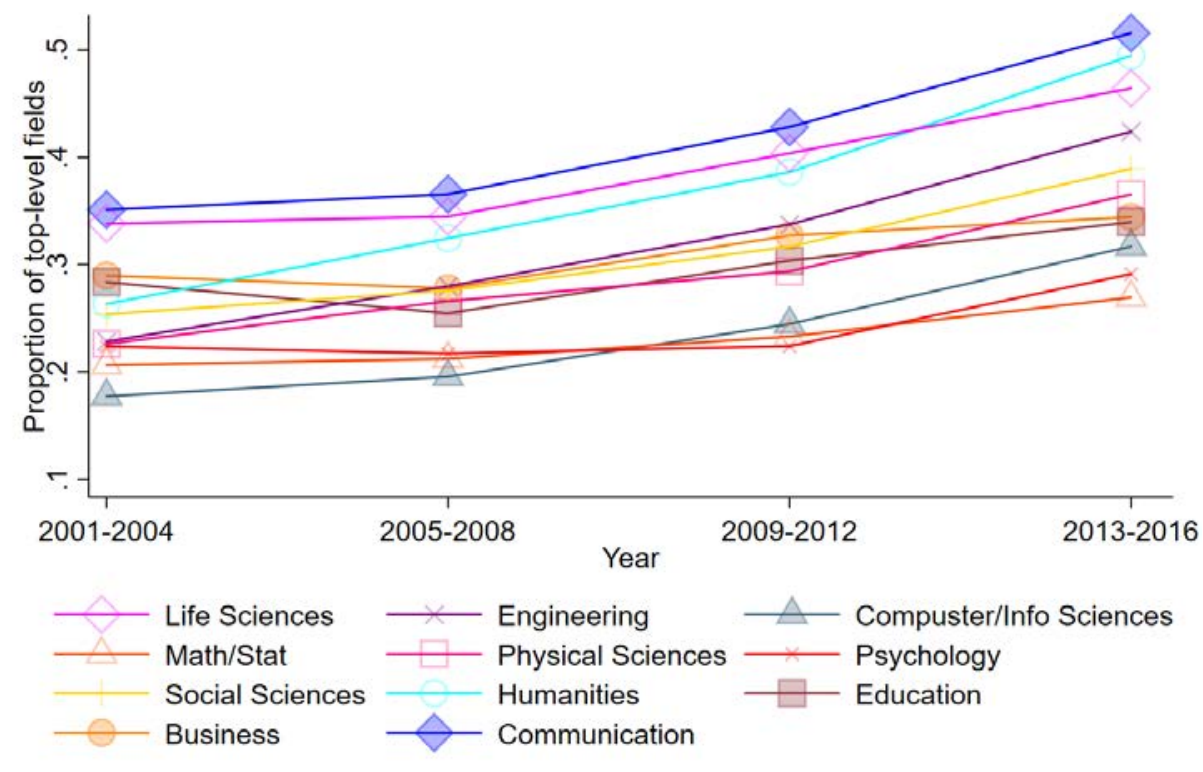

C.

Life Sciences(39.38\%)

Life Sciences

Engineering $(33.03 \%)$

Engineering

Compuster/lnfo Sciences $(24.69 \%)$ Computer/lnfo Sciences Math/Stat(23.48\%) Math/Stat

Physical Sciences $(29.43 \%) \quad$ Physical Sciences

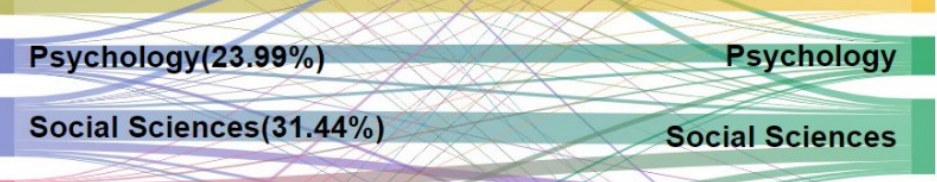

\begin{tabular}{|lr|} 
Humanities(36.82\%) & Humanities \\
\hline Education $(29.25 \%)$ & Education \\
\hline $\begin{array}{l}\text { Business }(31.20 \%) \\
\text { Communication(42.39\%) }\end{array}$ & Business \\
\hline
\end{tabular}


Figure 2: Sample means and proportions for outcomes and characteristics of $\mathrm{PhD}$ recipients. A shows how "local" interdisciplinarians have consistently earned salaries markedly lower than others across the sample period while "global" interdisciplinarians and monodisciplinarians earn salaries above the baseline of the overall population. B shows how placement varies depending on the (inter)disciplinary status of a person's dissertation with notable differences in, respectively, lower- and higher-paying postdoc and industry positions. $\mathrm{C}$ shows relatively little variation with respect to the background characteristics of doctoral graduates in relation to their dissertations (inter)disciplinary status. Data are for earned doctorates in the United States and span 2001-20016 for placements and 2008-2016 for salary. All data are from the Survey of Earned Doctorates (SED).

A.

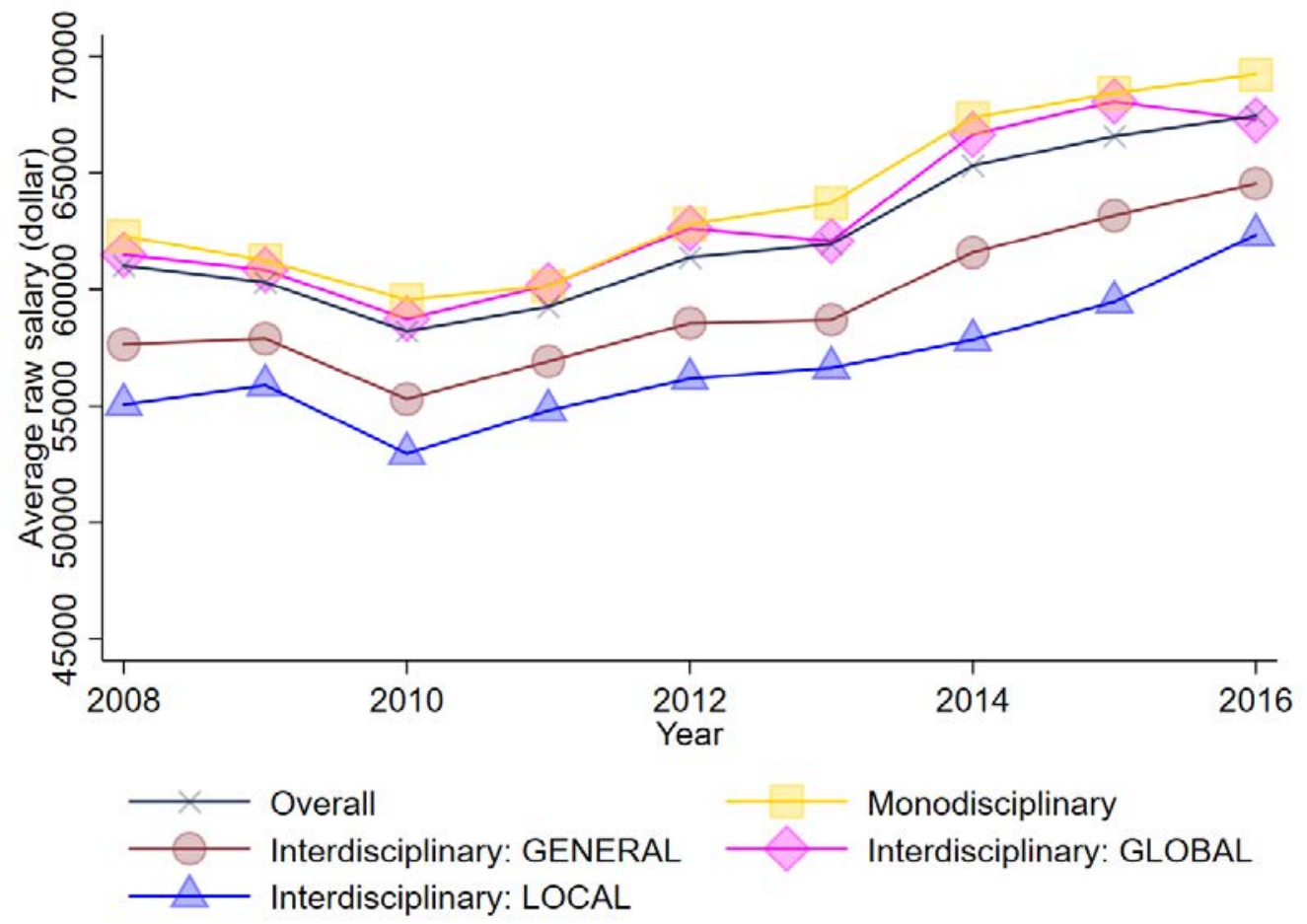


B.

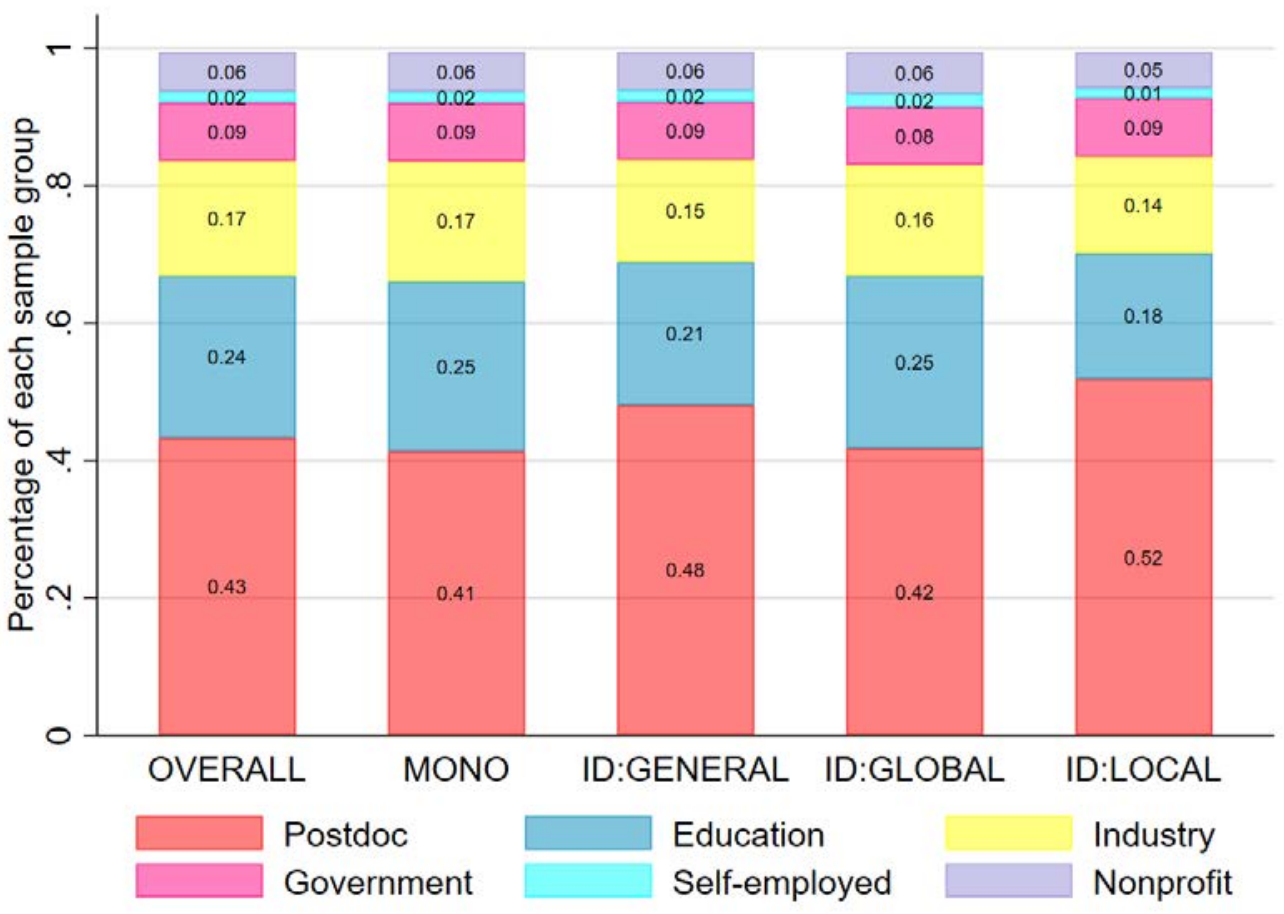

C.

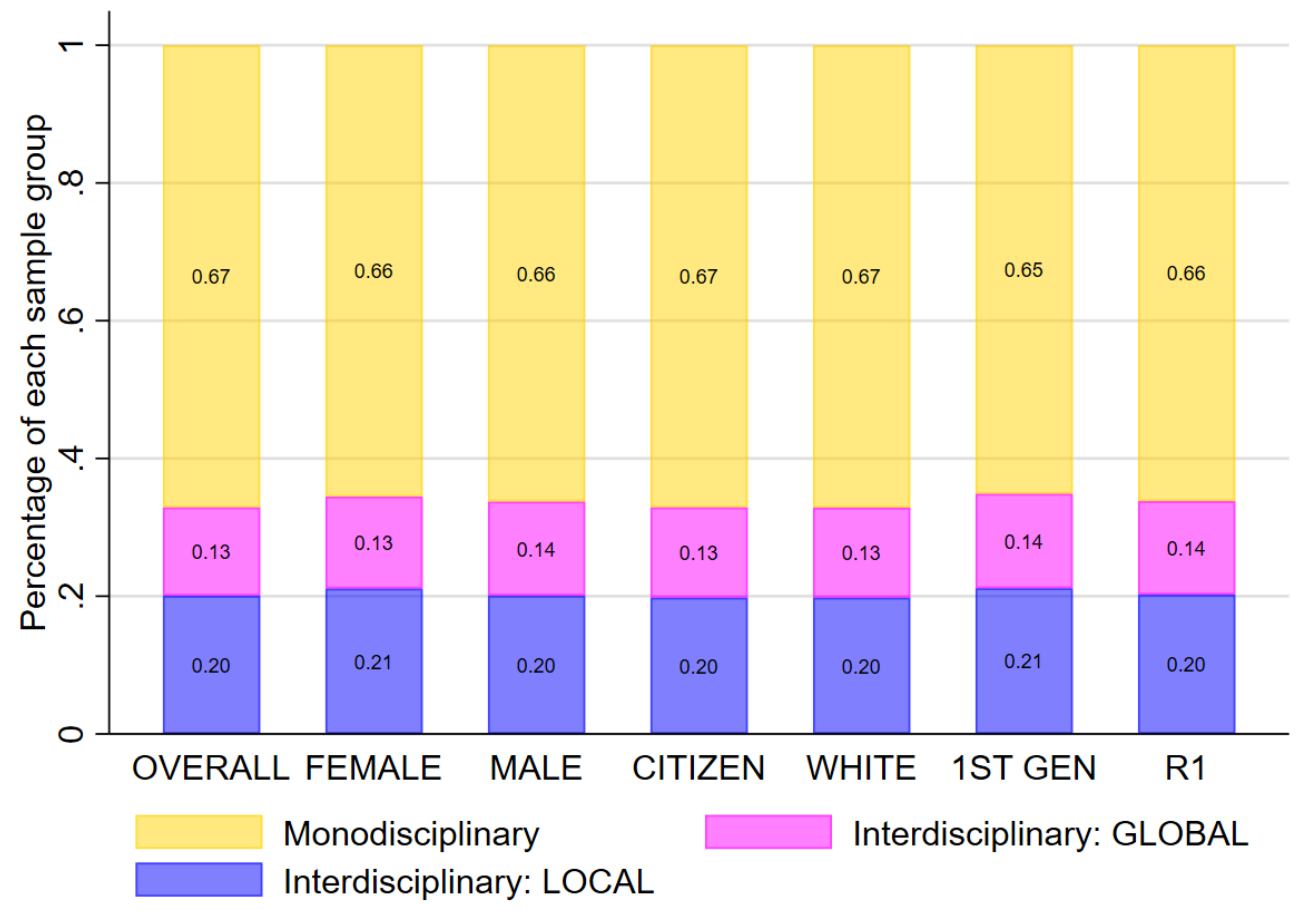


Figure 3: Average model-estimated salaries by (inter-)disciplinary status. Monodisciplinary dissertators tend to show an advantage in the higher-paying fields (Engineering, Business) while global interdisciplinarians tend to show an advantage in lower-paying fields (Life Sciences, Math, Humanities). Estimates are based on the Survey of Earned Doctorates (SED) for people who earned the PhD in the United States between 2008 through 2016.

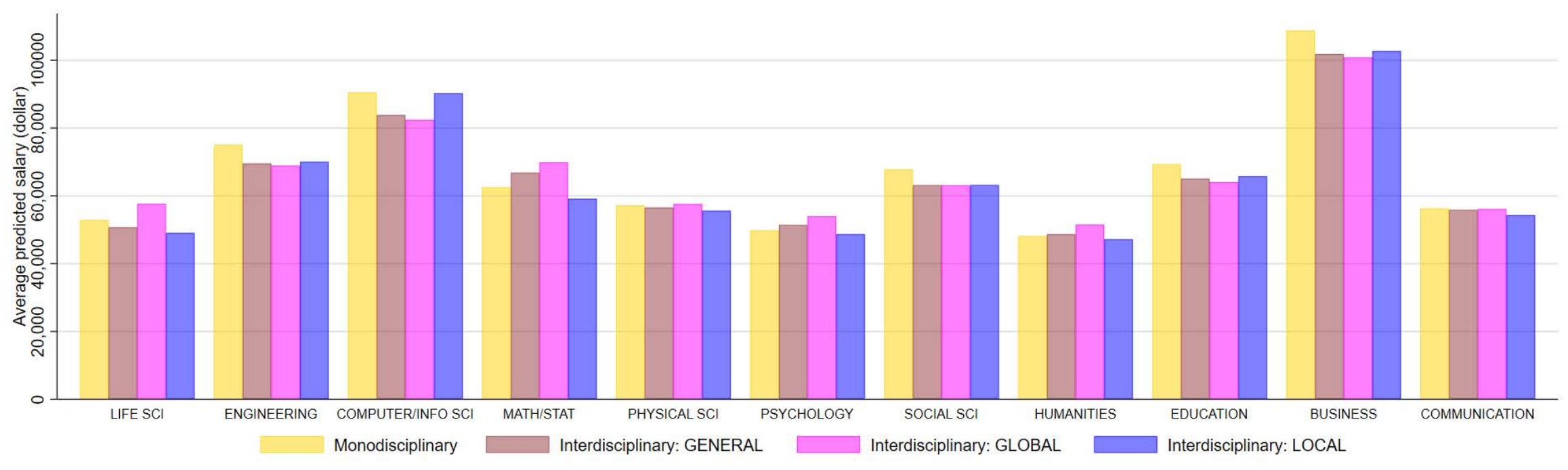


Table 1. Sample Means for outcomes based on all Survey of Earned Doctorates (SED) respondents, 2001-2016

\begin{tabular}{|c|c|c|c|c|c|}
\hline Placement(\%) & Full sample & $\begin{array}{c}\text { Mono- } \\
\text { disciplinary }\end{array}$ & $\begin{array}{c}\text { General } \\
\text { Interdisc }\end{array}$ & $\begin{array}{c}\text { Global } \\
\text { Interdisc }\end{array}$ & $\begin{array}{c}\text { Local } \\
\text { Interdisc }\end{array}$ \\
\hline Education & $23.65 \%$ & $24.75 \%$ & $20.86 \%$ & $25.17 \%$ & $18.38 \%$ \\
\hline Postdoc position & $43.29 \%$ & $41.36 \%$ & $48.07 \%$ & $41.77 \%$ & $51.89 \%$ \\
\hline Industry & $16.67 \%$ & $17.44 \%$ & $14.81 \%$ & $16.10 \%$ & $13.94 \%$ \\
\hline Government & $8.52 \%$ & $8.52 \%$ & $8.53 \%$ & $8.42 \%$ & $8.61 \%$ \\
\hline Self-employed & $1.60 \%$ & $1.61 \%$ & $1.59 \%$ & $1.89 \%$ & $1.39 \%$ \\
\hline Non-profit & $5.79 \%$ & $5.86 \%$ & $5.66 \%$ & $6.16 \%$ & $5.32 \%$ \\
\hline Time to degree & & & & & \\
\hline $\begin{array}{c}\text { Years as } \\
\text { Graduate }\end{array}$ & 6.91 & 6.93 & 6.87 & 7.03 & 6.81 \\
\hline Student & & & & & \\
\hline
\end{tabular}


Table 2. Sample Means for Background Characteristics of all Survey of Earned Doctorates (SED) respondents, 2001-2016

\begin{tabular}{|c|c|c|c|c|c|}
\hline Demographics & Full sample & $\begin{array}{c}\text { Mono- } \\
\text { disciplinary }\end{array}$ & $\begin{array}{c}\text { General } \\
\text { Interdisc }\end{array}$ & $\begin{array}{c}\text { Global } \\
\text { Interdisc }\end{array}$ & $\begin{array}{c}\text { Local } \\
\text { Interdisc }\end{array}$ \\
\hline Age (years) & 35.3 & 35.1 & 35.5 & 36.2 & 35.1 \\
\hline Female & $45.9 \%$ & $45.5 \%$ & $46.5 \%$ & $45.5 \%$ & $47.2 \%$ \\
\hline US citizen & $65.1 \%$ & $66.3 \%$ & $63.0 \%$ & $63.2 \%$ & $62.8 \%$ \\
\hline White & $66.3 \%$ & $67.7 \%$ & $64.0 \%$ & $64.1 \%$ & $63.9 \%$ \\
\hline 1st-gen college & $33.3 \%$ & $33.3 \%$ & $33.2 \%$ & $33.3 \%$ & $33.2 \%$ \\
\hline R1 school & $78.3 \%$ & $79 . \%$ & $78.9 \%$ & $79.8 \%$ & $78.3 \%$ \\
\hline Graduate Research & $59.2 \%$ & $58.8 \%$ & $60.3 \%$ & $61.7 \%$ & $59.3 \%$ \\
\hline Assistant & & & & & \\
\hline
\end{tabular}


Table 3. Sample Means for Salaries Across Top-Level Fields of all Survey of Earned Doctorates (SED) respondents, 2001-2016

\begin{tabular}{|c|c|c|c|c|c|}
\hline Near-term Salary (\$) & $\begin{array}{c}\text { Full } \\
\text { sample }\end{array}$ & $\begin{array}{c}\text { Mono- } \\
\text { disciplinary }\end{array}$ & $\begin{array}{c}\text { General } \\
\text { Interdisc }\end{array}$ & $\begin{array}{c}\text { Global } \\
\text { Interdisc }\end{array}$ & $\begin{array}{c}\text { Local } \\
\text { Interdisc }\end{array}$ \\
\hline Overall & 62392.33 & 63673.04 & 59665.73 & 63546.64 & 56999.67 \\
\hline Life Science & 51984.74 & 52883.42 & 50751.25 & 57676.50 & 49078.87 \\
\hline Engineering & 73021.09 & 75064.79 & 69552.96 & 68915.72 & 70059.07 \\
\hline Computer Science & 88781.62 & 90523.42 & 83842.06 & 82452.59 & 90307.27 \\
\hline Mathematics & 63616.33 & 62556.87 & 66844.47 & 69944.40 & 59178.06 \\
\hline Physical Science & 56996.35 & 57202.92 & 56557.18 & 57614.52 & 55625.22 \\
\hline Psychology & 50203.18 & 49801.30 & 51432.52 & 53994.97 & 48694.59 \\
\hline Social science & 66337.45 & 67827.24 & 63162.11 & 63134.64 & 63190.31 \\
\hline Humanities & 48398.91 & 48180.33 & 48697.36 & 51520.07 & 47214.42 \\
\hline Education & 68124.88 & 69341.28 & 65101.39 & 64077.36 & 65805.01 \\
\hline Business & 106721.60 & 108798.20 & 101834.19 & 100886.00 & 102758.60 \\
\hline Communication & 56132.76 & 56340.75 & 55866.93 & 56118.24 & 54316.21 \\
\hline
\end{tabular}


Appendix

Dissertators with Distantly Related Foci

Face Divergent Near-Term Outcomes 
Figure A1. Based on ProQuest data, Figure A1 mirrors Figure 1 with the benefit of a deeper historical timeframe.

A.

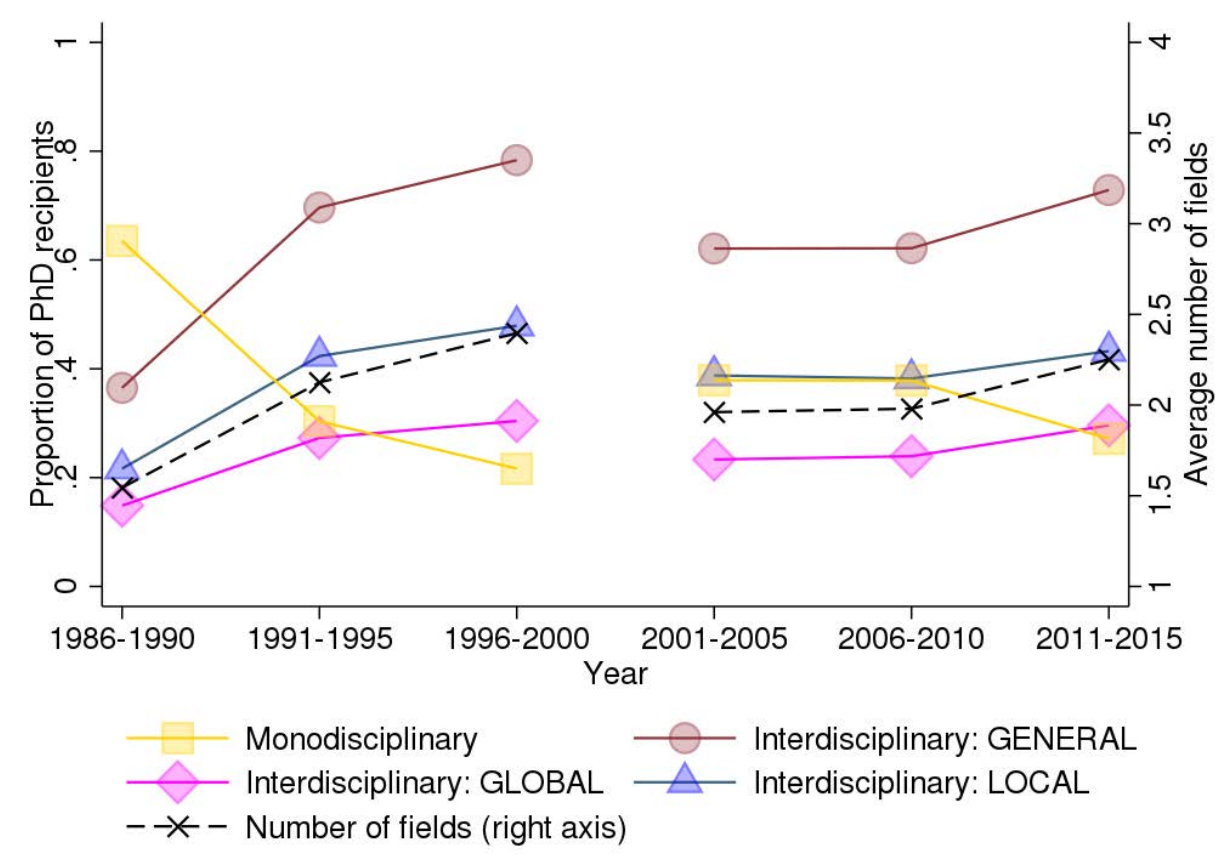


B.

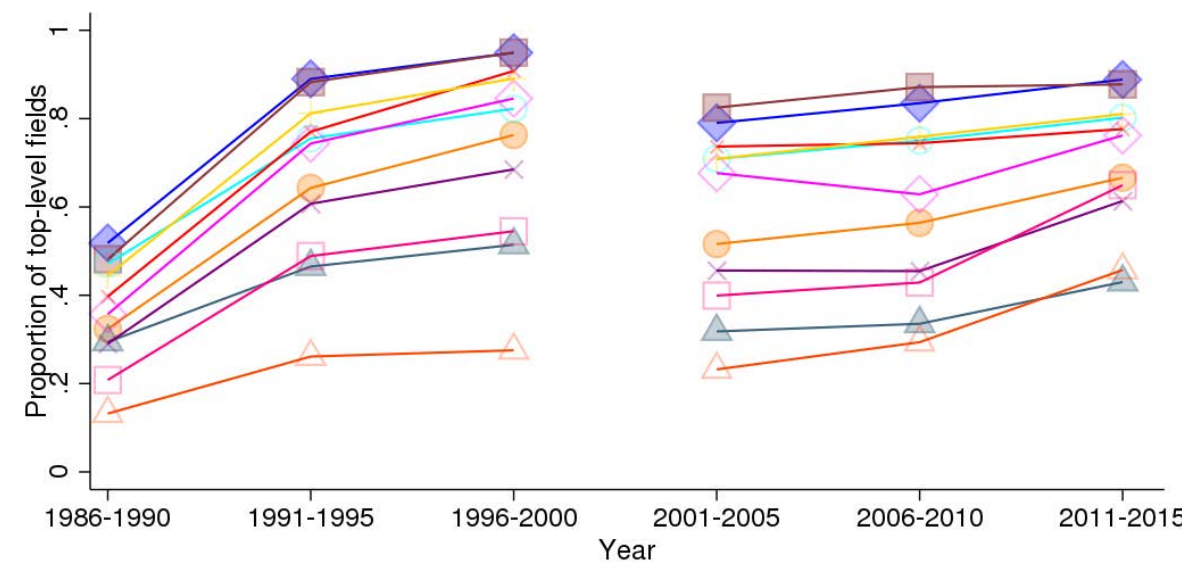

C.

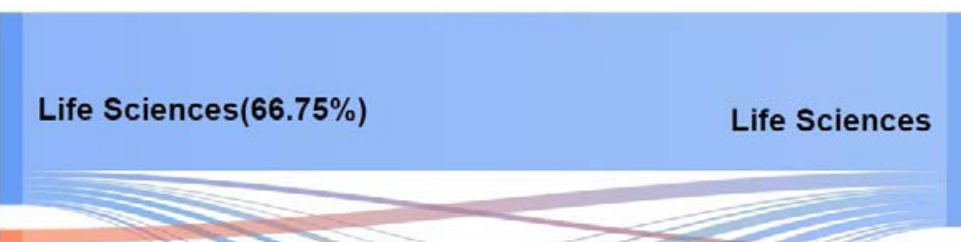

Engineering( $51.77 \%)$

Engineering

Compuster/Info Sciences $(38.82 \%)$ Computer/Info Sciences Math/Stat $(29.14 \%)$ Math/Stat Physical Sciences $(44.89 \%) \quad$ Physical Sciences

Psychology(71.46\%) Psychology

Social Sciences $(74.43 \%) \quad$ Social Sciences

Social Sciences $(74.43 \%) \quad$ Social Sciences

Humanities $\mathbf{( 7 2 . 3 3 \% )}$ Humanities

\begin{tabular}{lr} 
Education $(81.10 \%)$ & Education \\
\hline Business $(57.53 \%)$ & Business \\
\hline Communication $(81.34 \%)$ & Communication \\
\hline
\end{tabular}


Figure A2. Complementing Figure 1C, these diagrams show the pairings of fields for three sub-periods of the full sample characterized in Figure 1C.

\section{A. 2001-2005}

\begin{tabular}{ll} 
Life Sciences $(34.00 \%)$ & Life Sciences \\
\hline Engineering $(24.59 \%)$ & Engineering
\end{tabular}

Compuster/lnfo Sciences $(19.13 \%)$ Computer/lnfo Sciences Math/Stat(21.19\%) Math/Stat

Physical Sciences $(23.85 \%) \quad$ Physical Sciences

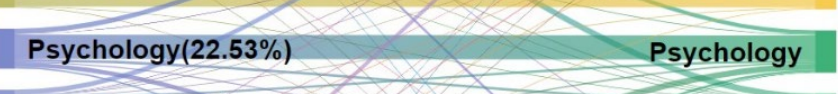

Social Sciences $(26.04 \%) \quad$ Social Sciences

Humanities $(27.64 \%)$

Humanities $(27.64 \%)$

Education

Education(27.92\%)

Business

Business $(29.43 \%)$

Communication(35.52\%) Communication

\section{B.2006-2010}

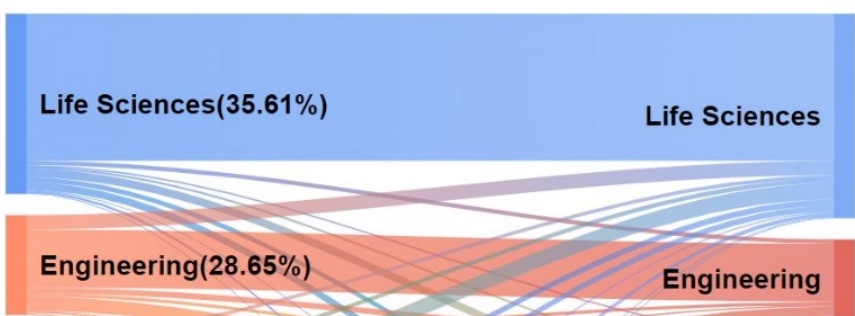

Compuster/linfo Sciences $(20.13 \%)$ Computer/lnfo Sciences $\begin{array}{ll}\text { Math/Stat }(21.06 \%) & \text { Math/Stat } \\ \text { Physical Sciences }(26.60 \%) & \text { Physical Sciences }\end{array}$

\begin{tabular}{|cc|} 
Physical Sciences(26.60\%) & Physical Sciences \\
\hline Psychology(21.07\%) & Psychology
\end{tabular}

Social Sciences $(28.52 \%) \quad$ Social Sciences

\begin{tabular}{|c|c|}
\hline Humanities(33.41\%) & Humanities \\
\hline Education(26.08\%) & Education \\
\hline
\end{tabular}

\section{C.2011-2016}

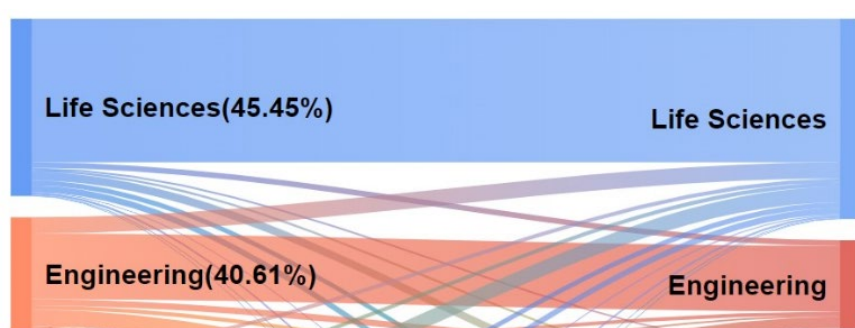

Compuster/lnfo Sciences $(30.10 \%)$ Computer/lnfo Sciences Math/Stat(26.33\%) Math/Stat Physical Sciences(34.87\%) Physical Sciences

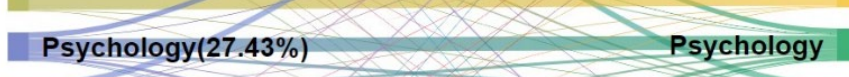

Social Sciences $(37.21 \%) \quad$ Social Sciences

\begin{tabular}{|lr}
\hline Humanities $(\mathbf{4 6 . 9 2 \% )}$ & Humanities \\
\hline Education(33.98\%) & Education \\
\hline Communication $(49.69 \%)$ & Business \\
\hline- Business $(34.84 \%)$ & Communication \\
\hline
\end{tabular}


Figure A3. Depictions of Salary Outcomes based on different "controls.” As complements to Figure 2, A controls for demographic characteristics: parental education, marital status, gender, race, US citizenship, B adds institutional types, C adds top-level disciplinary categories, and D adds placement.

\section{A. Demographics controlled (basic controls)}

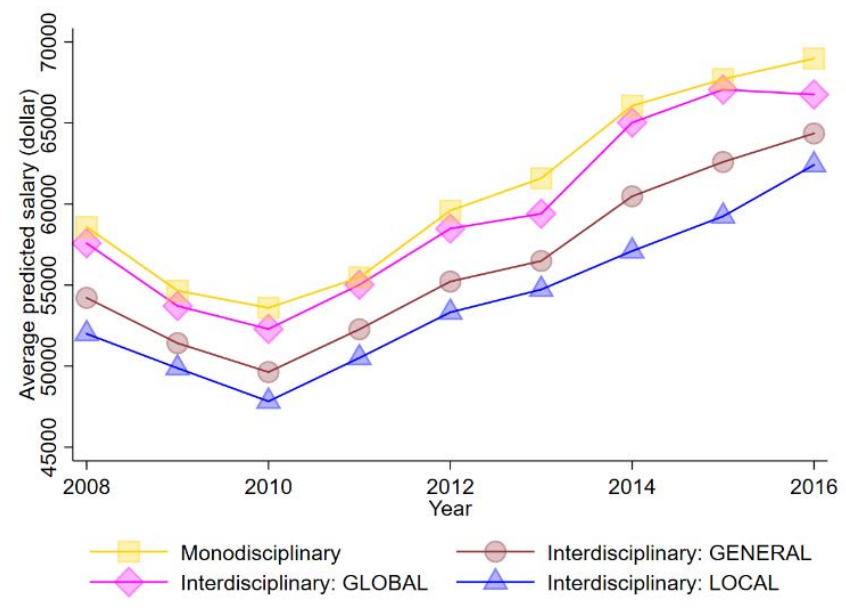

C. Demographics, institution characteristics, and field controlled

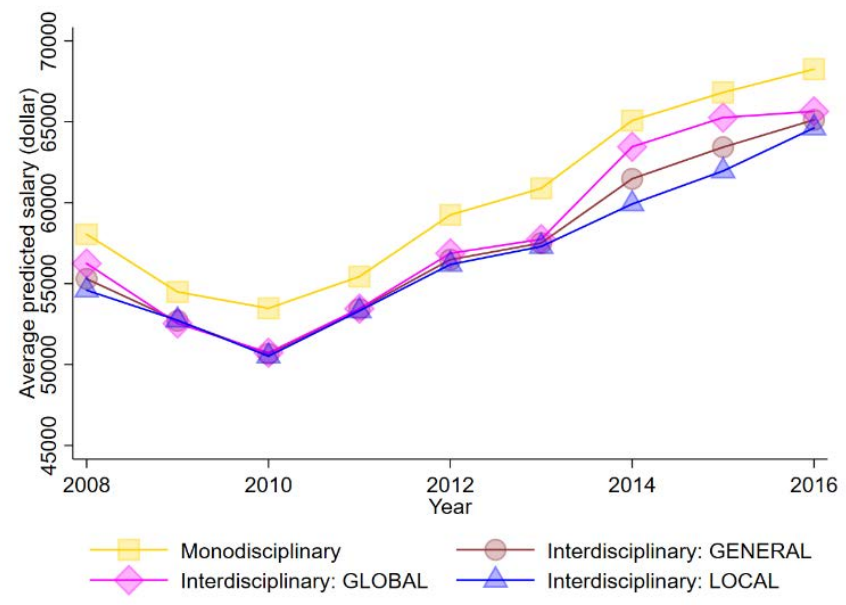

B. Demographics and institution characteristics controlled

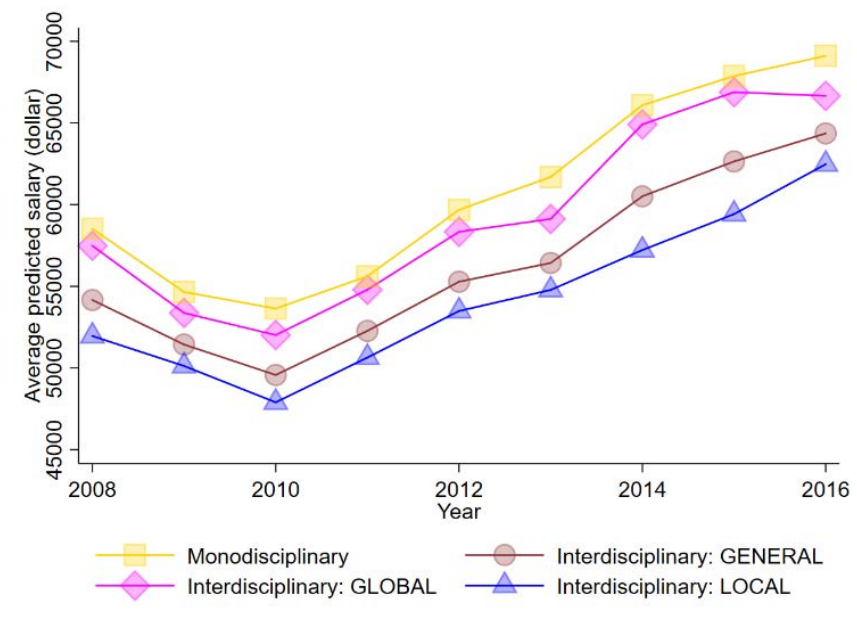

D. Demographics, institution characteristics, field and placement controlled (full controls)

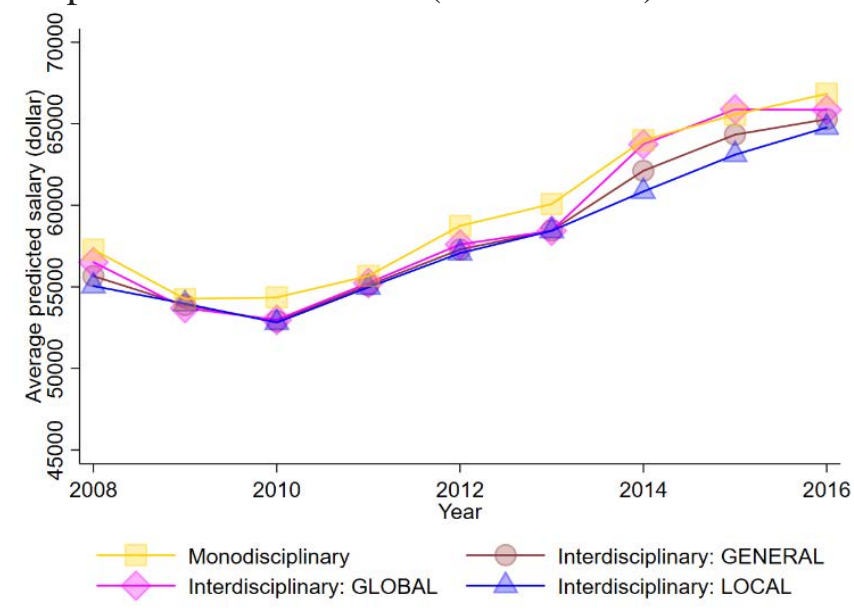

